\title{
Education in Diabetes Mellitus for blood glucose self-monitoring: a quasi-experimental study
}

\author{
Educação em Diabetes Mellitus para automonitorização da glicemia: estudo quase-experimental \\ Educación en Diabetes Mellitus para automonitorización de la glucemia: estudio cuasi-experimental
}

\section{Marcelo Henrique Barbosa Baptista'} ORCID: 0000-0002-4864-9170

Fernanda Cristina Dourado'

ORCID: 0000-0003-1719-8116

Danielle dos Santos Gomides' ORCID: 0000-0003-2870-2525

Carla Regina de Souza Teixeira' ORCID: 0000-0002-8887-5439

Maria Cristina Foss de Freitas' ORCID: 0000-0002-1350-1125

Ana Emilia Pace' ORCID: 0000-0002-0079-6913

Universidade de São Paulo. Ribeirão Preto, São Paulo, Brazil.

How to cite this article: Baptista MHB, Dourado FC, Gomides DS, Teixeira CRS, Freitas MCF, Pace AE. Education in Diabetes Mellitus for blood glucose self-monitoring: a quasiexperimental study. Rev Bras Enferm. 2019;72(6):1601-8. doi: http://dx.doi.org/10.1590/0034-7167-2018-0731

Corresponding Author:

Ana Emilia Pace

E-mail: aepace@eerp.usp.br

Submission: $12-02-2018$

Approval: 04-09-2019

\section{ABSTRACT}

Objective: to evaluate the contributions of an educational program for capillary blood glucose self-monitoring. Method: a quasi-experimental study performed in an outpatient unit of a tertiary health care service in a sample of 25 people with Type 2 Diabetes Mellitus, from July 2016 to December 2017, developed through interactive tools for care with capillary blood glucose self-monitoring. Results: among the items of capillary blood glucose self-monitoring that showed improvement after participation in the educational program, the most noteworthy are the "postprandial blood glucose values" $(p=0.0039)$, "Interpretation of capillary blood glucose results with meals and medications" ( $p=0.0156)$, "recognition of the 'weakness' symptom for hyperglycemia" ( $p=0.0386$ ) and "administration of medications correctly" for hyperglycemia prevention ( $p=0.0063)$. Conclusion: the study made it possible to recognize the main characteristics of blood glucose self-monitoring that may contribute to the care for the person with diabetes.

Descriptors: Diabetes Mellitus; Health Education; Blood Glucose Self-Monitoring; SelfCare; Nursing Care.

\section{RESUMO}

Objetivo: avaliar as contribuições de um programa educativo para a automonitorização da glicemia capilar. Método: estudo quase-experimental, realizado em unidade ambulatorial de um serviço de atenção terciária à saúde, em amostra de 25 pessoas com Diabetes Mellitus tipo 2, no período de julho de 2016 a dezembro de 2017, desenvolvido por meio de ferramentas interativas para o cuidado com a automonitorização da glicemia capilar. Resultados: entre os itens da automonitorização da glicemia capilar que apresentaram melhora após a participação no programa educativo, destacam-se os "valores da glicemia pós-prandial" $(p=0,0039)$, "interpretação dos resultados de glicemia capilar com as refeiçõese medicamentos" $(\mathrm{p}=0,0156)$, "reconhecimento do sintoma 'fraqueza' para a hiperglicemia" $(p=0,0386)$ e "administração de medicamentos corretamente" para prevenção da hiperglicemia $(p=0,0063)$. Conclusão: o estudo possibilitou reconhecer as principais características da automonitorização da glicemia que poderão contribuir para o cuidado à pessoa portadora da doença.

Descritores: Diabetes Mellitus; Educação em Saúde; Automonitorização da Glicemia; Autocuidado; Cuidados de Enfermagem.

\section{RESUMEN}

Objetivo: evaluar las contribuciones de un programa educativo para la automonitorización de la glucemia capilar. Método: el estudio cuasi-experimental, realizado en unidad ambulatoria de un servicio de atención terciaria a la salud, en muestra de 25 personas con Diabetes Mellitus tipo 2, en el período de julio de 2016 a diciembre de 2017, desarrollado por medio de herramientas interactivas para el cuidado con la automonitorización de la glucemia capilar. Resultados: entre los ítems de la automonitorización de la glucemia capilar que presentaron mejoría después de la participación en el programa educativo, se destacan los "valores de la glucemia postprandial" $(p=0,0039)$, "Interpretación de los resultados de glucemia capilar con las comidas y medicamentos" ( $p=0,0156)$, "reconocimiento del síntoma" debilidad "para la hiperglicemia" $(p=0,0386)$ y "administración de medicamentos correctamente" para prevenir la hiperglucemia $(p=0,0063)$. Conclusión: el estudio posibilitó reconocer las principales características de la automonitorización de la glucemia que pueden contribuir para el cuidado a la persona portadora de la enfermedad.

Descriptores: Diabetes Mellitus; Educación en Salud; Automonitorización de la Glucosa Sanguínea; Autocuidado; Atención de Enfermería. 


\section{INTRODUCTION}

Chronic hyperglycemia of diabetes mellitus (DM) is the main cause of the development of microvascular and macrovascular complications, with involvement in several organs and systems ${ }^{(1-2)}$. Therefore, the treatment consists in the control of blood glucose for the prevention and/or delay of these chronic complications $s^{(3-4)}$.

Through the importance of glycemic control, strategies that support behaviors favorable to its reach and maintenance should be a priority in care for the person with DM. In this perspective, DM education can be a fundamental strategy to promote knowledge and the development of self-care skills $s^{(2,5-6)}$.

When considering education as the basis for managing disease care, its development should address the person's current needs. In this context, the theoretical assumptions of Self-Efficacy (SE), one of the elements of the Cognitive Social Theory (CST), were used, which includes the relation between personal belief and its influence in the adoption and maintenance of a new behavior ${ }^{(7-8)}$. Personal beliefs are the basis of human motivation, so the educational process can positively influence acquiring and maintaining new behavioral practices, as well as influencing perseverance to overcome difficulties ${ }^{(8)}$.

Among the essential care activities in the present study, we will highlight those related to capillary blood glucose self-monitoring (CBGFM). CBGFM is considered an essential care activity to evaluate the efficacy of drug and non-drug treatment, mainly because it includes elements that may influence glycemic control such as diet, physical exercises, medications, emotions, presence of infections, and contribute to the development of care skills and promote the person's involvement in their self-care ${ }^{(1)}$.

A review of the literature in the last five years in the main databases has shown the scarcity of studies that address CBGFM care education, especially through interactive and easy-to-use tertiary care health. Therefore, the present study was proposed on the basis of this need for research expansion.

\section{OBJECTIVE}

To evaluate the contributions of an educational program for capillary blood glucose self-monitoring.

\section{METHOD}

\section{Ethical aspects}

The study was approved by the Research Ethics Committee (REC) from Escola de Enfermagem de Ribeirão Preto - USP and REC from Hospital das Clínicas of the Faculdade de Medicina de Ribeirão Preto - USP.

\section{Design, place of study and period}

This is a quasi-experimental study, with assessment before $\left(T_{0}\right)$ and after educational interventions $\left(T_{12}\right)$ developed in an outpatient unit of a municipal tertiary health service in the countryside of São Paulo State, from July 2016 to December 2017.

The present study is part of the matrix project called "Intervenções educativas em DM: estudo quase-experimental", composed of two quasi-experimental studies, whose samples came from the same base population.

\section{Sample, inclusion and exclusion criteria}

The sample consisted of people with Type 2 Diabetes Mellitus (2DM) of both genders, with a minimum diagnosis time of one year, minimum age of 40 years, who were able to respond verbally to the questionnaires, whose drug treatment was with insulin, associated with or not to the oral antidiabetic drug, in medical follow-up and that they had a glucose meter.

As exclusion criteria, people who participated in another educational program were undergoing hemodialysis, had a wheelchair and/or stretcher for locomotion, had amaurosis, disabling sequels of stroke/heart failure, previous amputations and/or active ulcer in lower limbs, severe psychiatric disorders, as well as impairment in cognitive processes as assessed by the Mini Mental State Examination (MMSE), were included ${ }^{(9)}$.

In order to carry out the selection of possible participants, it was verified in the electronic system of the health service visits during the period that included the study development study. Among the 7,402 visits, duplicate records and those who did not meet the established inclusion criteria were excluded, resulting in 210 people who could participate in the present study.

\section{Study protocol}

Sociodemographic characterization of the sample was performed using the following variables: gender, age, schooling, and family monthly income. For clinical variables: time of diagnosis of 2DM and glycated hemoglobin ( $\mathrm{HbA1c}$ ). Finally, for the drug treatment variable: type of medication used and treatment time, in complete years.

The results of $\mathrm{HbA} 1 \mathrm{c}$ used to evaluate glycemic control were obtained in the electronic system of the health service and were considered on average three months prior to the interview date for $\mathrm{T}_{0}$ and three months after $\mathrm{T}_{12}$ for collection post-interventions.

Sociodemographic, clinical data, and drug treatment were recorded in a structured tool developed by the Multidisciplinary Diabetes Care Research Group and used in a recent study ${ }^{(10)}$.

CBGFM variables were obtained, following the "Instrumento para Avaliar o Autocuidado com a Monitorização da Glicemia Capilar de Pessoas com Diabetes Mellitus"(11). This tool consists of 39 items with four themes: 1 - performance and frequency of monitoring of capillary blood glucose (items 1 to 7); 2 - knowledge of reference standards, record, and interpretation of results obtained (items 8 to 20); 3 - preparation, storage, and disposal of materials (items 21 to 31 ); and 4 - knowledge of signs/symptoms, prevention, and treatment of hypo and hyperglycemia (items 32 to 39).

This last tool was reviewed through validation of face and content by a group of seven professionals with experience in the area including the tool's author. The application of this tool was by interview and all questions were described in the results of the present study.

To develop educational interventions, Diabetes Conversation Maps were used, which is a tool developed by Healthy Interactions in collaboration with the International Diabetes Federation and translated into Brazilian Portuguese by Lilly. The protocol for interventions development was based on the facilitator's guide and adapted to the objectives of the study.

Diabetes Conversation Maps are made up of "tables" of paper, $1.0 \mathrm{~m}$ by $1.5 \mathrm{~m}$, with illustrations and short texts, which allow 
discussion among participants. Each map has conversation cards that allow you to direct the main subjects to be discussed in the meeting of the specific theme and encourage participants to express their opinions, knowledge, and experiences.

Conversation Maps sets targeted to people with type 2DM is made up of four maps: \#1: How the Body and Diabetes Work; \#2: Healthy Eating and Physical Activity; \#3: Drug Treatment and Blood Glucose Monitoring and \#4: Reaching the Goals with Insulin.

For the present study, considering the profile of people attending the health service, who have difficulty locomotion, attend consultations, on average, every three months and have limited time to participate in educational interventions, Maps of numbers 2 and 3 were used, since they included aspects related to treatment (medicated and non-medicated), CBGFM and glucose values.

Regarding educational interventions, the present study had five face-to-face moments, with an average interval of three months, following the routine of the interval between medical visits at the Health Unit, of which two were individually for the first $\left(T_{0}\right)$ and second $\left(T_{12}\right)$ data collection, respectively, and three moments for the development of educational interventions. In addition to these face-to-face interventions, seven interventions were carried out through telephone calls, according to the topics covered in face-to-face meetings.

The average duration of educational meetings was approximately 1 hour and 30 minutes, conducted by a nursing graduate and an undergraduate student (facilitators), both with research linked to the present study. Participants were organized in a semicircle and the map of the respective session was fixed to the wall, allowing visualization by all participants.

At all meetings, participants were invited to introduce themselves and then the facilitators performed visual presentation of the map. Groups were conducted in a way that the facilitators directed the topics through conversation cards and the creation of a favorable and pleasant environment for interaction among participants.

People recruitment to compose the study sample was performed at the time of the scheduled return in the Health Unit. Spreadsheets were elaborated with the dates of return of the 210 possible participants, so the medical records were again consulted to update the data regarding the criteria of inclusion/exclusion.

At the first meeting, an invitation was done to participate in the study. Those who agreed to participate were asked to sign the FICF in two copies. Next, the first data collection was performed $\left(T_{0}\right)$.

The second meeting aimed to discuss the topic of healthy eating and physical activity (Map 2) and its relation with glycemic control. At the third meeting, the topic discussed was drug treatment and blood glucose monitoring (Map 3).

At the fourth meeting, a discussion was held with an educational workshop to evaluate and interpret the blood glucose values obtained so far, behaviors related to these values and their relationship with diet, physical activity, and medication. The fifth and last meeting was to carry out the second data collection $\left(T_{12}\right)$.

Educational interventions through telephone contact were made through a specific protocol, developed by the researchers and based on a clinical trial ${ }^{(12)}$, according to the topics addressed in the group meetings. The protocol was structured in order to standardize all the information: goal of the connection, verification of behavioral changes, development of the specific theme, and doubts of participants. Telephone calls were monthly and interspersed with the group meetings, with an average duration of 20 minutes and aimed to motivate the person to report their doubts, as well as to reinforce the themes about CBGFM and care.

\section{Analysis of results and statistics}

The data was double-typed and validated in the MS-Excel program. The statistical analysis was performed by program $\mathrm{R}$ version 3.4.2.

To compare the laboratory variable, the Wilcoxon Signal Test was used. This is a non-parametric test that makes it possible to compare the results of each subject in the two study times. The McNemar test is non-parametric and used for paired samples. This allowed to evaluate, in a comparative way, each question of the CBGFM tool in $\mathrm{T}_{0}$ and $\mathrm{T}_{12}$. The significance level was $5 \%(\mathrm{a}=0.05)$.

\section{RESULTS}

The final sample of the study consisted of 25 people (Figure 1).

Regarding sociodemographic characterization, the sample consisted of 14 (56.0\%) male participants and 11 (44.0\%) female participants, with mean age of $60.16(S D=8.58)$ years, and mean schooling time of 7.06 ( $S D=5.02)$ complete years of study. The average monthly family income of the study participants was $2,520.80$ ( $S D=1614.68$ ) reais (reais is the Brazilian currency).

The mean 2DM diagnosis time was $17.28(S D=8.22)$ years. It was a long time, but consistent with the level of tertiary health care.

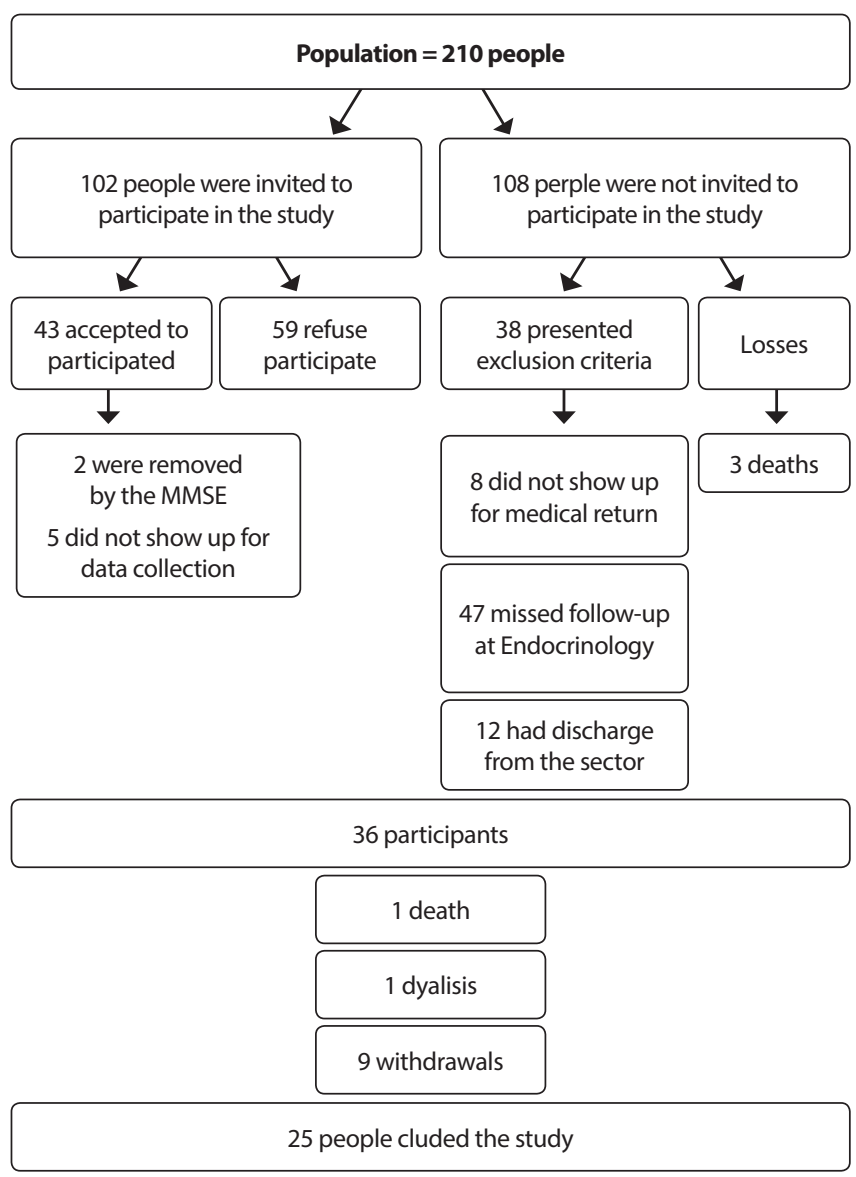

Figure 1 - Study sample, Ribeirão Preto, São Paulo, Brazil, 2018 
All 25 (100\%) participants used insulin, with an average time of $7.39(\mathrm{SD}=6.04)$ years. The use of oral antidiabetic drugs (OADD) was reported by $16(64 \%)$ participants before the educational program and 17 (68\%) after the educational program. The mean duration of OADD use was $14.56(S D=8.14)$ years.

In the result concerning assessment of glycemic control, it is noteworthy that the mean $\mathrm{HbA} 1 \mathrm{c}$ remained the same before and after participation in the educational program, with an average value of $9.01 \%$, and respective Standard Deviation of 2.15 in $\mathrm{T}_{0}$ and 1.64 in the $T_{12}$. When analyzing the HbA1c interval, in the two study times, there was variation from $6.30 \%$ to $15.10 \%$ in $\mathrm{T}_{0}$ and from $6.20 \%$ to $12.30 \%$ in $\mathrm{T}_{12}$. Regarding the CBGFM variable, in theme 1 there were no significant changes between the two times (Table 1).

Table 1 - Performance and frequency of capillary blood glucose self-monitoring (CBGFM) of the studied sample, before and after participation in the educational program, Ribeirão Preto, São Paulo, Brazil, 2018

\begin{tabular}{|c|c|c|c|}
\hline Items & Frequency (\%) $\mathrm{T}_{0}$ & Frequency $(\%) T_{12}$ & $p$ value \\
\hline \multicolumn{4}{|l|}{1 - Performs capillary blood glucose monitoring } \\
\hline Always & $24(96.0)$ & $23(92.0)$ & \multirow[b]{2}{*}{1.0} \\
\hline Sometimes & $1(4.0)$ & $2(8.0)$ & \\
\hline \multicolumn{4}{|l|}{5 - How many days a day does the test } \\
\hline Every day ( 7 times) & $12(48.0)$ & $14(56.0)$ & \multirow{7}{*}{0.6816} \\
\hline Six times & $1(4.0)$ & $0(0.0)$ & \\
\hline Five times & $0(0.0)$ & $1(4.0)$ & \\
\hline Alternate days ( 4 teams) & $1(4.0)$ & $2(8.0)$ & \\
\hline Alternate Days (3 times) & $6(24.0)$ & $2(8.0)$ & \\
\hline Twice & $3(12.0)$ & $3(12.0)$ & \\
\hline Once & $2(8.0)$ & $3(12.0)$ & \\
\hline \multicolumn{4}{|l|}{6 - How many times a day performs the test } \\
\hline Once & $6(24.0)$ & $2(8.0)$ & \multirow{5}{*}{0.0998} \\
\hline Twice & $0(0.0)$ & $6(24.0)$ & \\
\hline 3 times & $3(12.0)$ & $5(20.0)$ & \\
\hline Four times & $6(24.0)$ & $5(20.0)$ & \\
\hline Five times & $10(40.0)$ & $7(28.0)$ & \\
\hline \multicolumn{4}{|l|}{ 7-Schedules for the test performance } \\
\hline Fasting & $24(96.0)$ & $25(100)$ & 1.0 \\
\hline Preprandial & $20(80.0)$ & $18(72.0)$ & 0.6250 \\
\hline Postprandial & $20(80.0)$ & $19(76.0)$ & 1.0 \\
\hline Before bedtime & $15(60.0)$ & $14(56.0)$ & 1.0 \\
\hline Dawn & $5(20.0)$ & $4(16.0)$ & 1.0 \\
\hline
\end{tabular}

Note: $p$ value-McNemar Test.

Table 2 - Knowledge of the reference standards, registration, and interpretation of results obtained in the capillary blood glucose self-monitoring (CBGFM) of the sample studied, before and after participation in the educational program, Ribeirão Preto, São Paulo, Brazil, 2018

\begin{tabular}{|c|c|c|c|}
\hline Items & Frequency (\%) $\mathrm{T}_{0}$ & Frequency $(\%) T_{12}$ & $p$ value \\
\hline \multicolumn{4}{|l|}{8 - Values for fasting blood glucose } \\
\hline 80 to 130 & $17(68)$ & $20(80.0)$ & 0.5078 \\
\hline Does not know & $7(28.0)$ & $4(16.0)$ & \\
\hline Incorrect & $1(4.0)$ & $1(4.0)$ & \\
\hline \multicolumn{4}{|l|}{9 - Values for blood glucose two hours after meals } \\
\hline$<180$ & $13(52.0)$ & $22(88.0)$ & 0.0039 \\
\hline Does not know & $11(44.0)$ & $3(12.0)$ & \\
\hline Incorrect & $1(4.0)$ & $0(0.0)$ & \\
\hline \multicolumn{4}{|l|}{11 - Had guidance on the use of the device } \\
\hline Yes & $19(76.0)$ & $21(84.0)$ & 0.6875 \\
\hline No & $6(24.0)$ & $4(16.0)$ & \\
\hline \multicolumn{4}{|l|}{13 - Had guidance on tests schedules } \\
\hline Yes & $14(56.0)$ & $12(48.0)$ & 0.7905 \\
\hline No & $11(44.0)$ & $13(52.0)$ & \\
\hline \multicolumn{4}{|l|}{15 - Had guidance on tests interpretation } \\
\hline Yes & $10(40.0)$ & $9(36.0)$ & 1.0 \\
\hline No & $15(60.0)$ & $16(64.0)$ & \\
\hline \multicolumn{4}{|c|}{17 - Interprets the result of capillary blood glucose relating to meals and medicines } \\
\hline Yes & $18(72.0)$ & $25(100.0)$ & 0.0156 \\
\hline No & $7(28.0)$ & $0(0.0)$ & \\
\hline \multicolumn{4}{|c|}{18 - Every time he/she takes the test. writes in the diary } \\
\hline Yes & $21(84.0)$ & $25(100.0)$ & 0.1353 \\
\hline No & $2(8.0)$ & $0(0.0)$ & \\
\hline Sometimes & $2(8.0)$ & $0(0.0)$ & \\
\hline \multicolumn{4}{|l|}{19 - Receives the inputs by the municipality } \\
\hline Yes & $23(92.0)$ & $24(96.0)$ & 1.0 \\
\hline No & $2(8.0)$ & $1(4.0)$ & \\
\hline
\end{tabular}

Note: $p$ value - McNemar Test. 
Table 3 - Knowledge, prevention, and treatment of hypo and hyperglycemia in the sample studied before and after participation in the educational program. Ribeirão Preto, São Paulo, Brazil, 2018

\begin{tabular}{|c|c|c|c|}
\hline Items & Frequency (\%) $\mathrm{T}_{0}$ & Frequency (\%) $T_{12}$ & $p$ value \\
\hline \multicolumn{4}{|l|}{32 - Knows what hypoglycemia is } \\
\hline Yes & $21(84.0)$ & $23(92.0)$ & 0.6250 \\
\hline \multicolumn{4}{|l|}{34 - Conduct in hypoglycemia } \\
\hline Performs the capillary blood glucose test & $11(44.0)$ & $10(40.0)$ & 1.0 \\
\hline Ingests quick-acting carbohydrates & $25(100.0)$ & $25(100.0)$ & - \\
\hline After 15 minutes, check again & $4(16.0)$ & $4(16.0)$ & 1.0 \\
\hline Seeks medical care & $0(0.00)$ & $0(0.00)$ & - \\
\hline \multicolumn{4}{|l|}{35 - Hypoglycemia prevention } \\
\hline Frequently performs capillary blood glucose test & $3(12.0)$ & $5(20.0)$ & 0.7266 \\
\hline Follows the regular meal plan & $20(80.0)$ & $23(92.0)$ & 0.3750 \\
\hline Consume protein-rich foods before bed & $0(0.00)$ & $1(4.0)$ & 1.00 \\
\hline Administers medications correctly & $2(8.0)$ & $6(24.0)$ & 0.2188 \\
\hline Eats before physical activities & $0(0.00)$ & $3(12.0)$ & 0.2500 \\
\hline Avoids ingestion of alcoholic beverages & $0(0.00)$ & $4(16.0)$ & 0.1250 \\
\hline Does not know & $1(4.0)$ & $1(4.0)$ & 1.0 \\
\hline \multicolumn{4}{|l|}{36 - Knows what hyperglycemia is } \\
\hline Yes & $23(92.0)$ & $23(92.0)$ & 1.0 \\
\hline \multicolumn{4}{|l|}{38 - Conduct in hyperglycemia } \\
\hline Performs the capillary blood glucose test & $6(24.0)$ & $7(28.0)$ & 1.00 \\
\hline Ingests water & $3(12.0)$ & $9(36.0)$ & 0.1094 \\
\hline Seeks medical care & $4(16.0)$ & $8(32.0)$ & 0.2891 \\
\hline Administers prescribed/doctor-guided insulin & $11(44.0)$ & $7(28.0)$ & 0.2891 \\
\hline Administers insulin on one's own & $1(4.0)$ & $3(12.0)$ & 0.5000 \\
\hline Does not do anything & $2(8.0)$ & $2(8.0)$ & 1.00 \\
\hline Does not know & $2(8.0)$ & $0(0.00)$ & 0.5000 \\
\hline Checks the medical prescription & $0(0.00)$ & $1(4.0)$ & 1.00 \\
\hline \multicolumn{4}{|l|}{39 - Hyperglycemia prevention } \\
\hline Often performs the capillary blood glucose test & $2(8.0)$ & $6(24.0)$ & 0.2891 \\
\hline Follows the reqular meal plan & $22(88.0)$ & $23(92.0)$ & 1.00 \\
\hline Manages medications correctly & $1(4.0)$ & $11(44.0)$ & 0.0063 \\
\hline Plan for physical activity & $2(8.0)$ & $5(20.0)$ & 0.3750 \\
\hline Does not know & $1(4.0)$ & $0(0.00)$ & 1.00 \\
\hline
\end{tabular}

Note: $p$ value-McNemar Test.

The main reason for CBGFM (item 2) was "to monitor blood glucose". In $\mathrm{T}_{0^{\prime}}$ one person reported that he asked the family member to perform the test and in $\mathrm{T}_{12}$, two people (item 3 ). Item 4 asks about the reason for not performing the test, but all participants answered that they always do or sometimes (data not presented in table).

In item 2, there was an increase in the frequencies of items on knowledge of postprandial glucose values and interpretation of glycemic values $(p<0.005)$ (Table 2$)$. All participants had a glucose meter (item 10).

Participants were questioned about the professional who advised how to use the device and the highest frequency of responses was" "nurse" (item 12). The professional who was most frequently referred to in the orientation on test times was "doctor" (item 14). In relation to the professional who guided the interpretation of the tests, in $\mathrm{T}_{0}$ the highest frequencies were for the "medical" professional and in $\mathrm{T}_{12}$ "other professionals" (item 16).

When questioning participants about the amount of tests that can be done in the month, the highest response frequency was for the category of 20 to 50 tests (item 20).

For item 3, the questions about "calibration of the tape-code glucose meter" (item 21), "verification of the expiration date of the reagent tape" (item 22), "tape storage at a suitable location" (item 23), "possession of the lancet (pen)" (item 24), "changing the lancet's graduation according to need" (item 25), "handwashing before performing CBGFM" (item 29), "performing antisepsis with $70 \%$ cotton and alcohol before performing puncture" (item
30) and "finger drying after 70\% alcohol antisepsis" (item 31 ) presented increased frequencies $(p>0.005)$.

The number of participants who shared lancet (pen) decreased from $8(38.1 \%)$ to $3(12.5 \%)$ (item 26$)$ with $>0.05 p$ value.

The disposal site of lancets (item 27) and tapes (item 28), referred more frequently in both study times, was the pet bottle.

When comparing the items contained in topic \# 4 on the signs and symptoms of hypoglycemia (item 33), 25 (100\%) participants reported seizures at $\mathrm{T}_{0}$ and $\mathrm{T}_{12}$. In the question about the signs and symptoms of hyperglycemia (item 37 ) reported by participants, the "weakness" symptom presented a statistical difference when it was reported in $\mathrm{T}_{0}$ by $5(20.0 \%)$ and in $\mathrm{T}_{12}$ by $13(52.0 \%)$ people $(p<0.005)$.

In the question on "hypoglycemia prevention" there was an increase for the category "administrates medications correctly" $(p<0.05)$ (Table 3).

\section{DISCUSSION}

The sample studied was composed mostly of elderly adults, with low monthly family income and low schooling. This sociodemographic profile reiterates the appropriateness of the educational strategy used, since it is a playful, interactive and easy to understand tool.

The application of the SE in the group context and telephone contact, from the themes developed through Conversation Maps, is favorable considering that the beliefs of SE originate from four 
sources called "Personal Experiences,"'“Vicarious Learning,"'”Verbal Persuasion", and "Physiological Information"(7).

In the group meetings, the "Personal Experiences" were reinforced by participants' reports on their abilities for self-care practices; "Vicarious Learning" could be strengthened by comparing and exchanging experiences among participants; "Verbal Persuasion" was mediated by the facilitator and strengthened in telephone calls, through verbal encouragement, to persuade the person she had to succeed in an activity and to encourage her to overcome the challenges; and the fourth source called "Physiological Information" was strengthened through support to address feelings unfavorable to care as well as increased motivation to cope with stressful situations expressed during face-to-face meetings and telephone contacts.

Regarding the contribution of the interventions to the $\mathrm{HbA} 1 \mathrm{c}$ results of the studied sample, no reductions in mean values were observed as expected after participation in the educational program. The number of educational meetings and the time limitation of participants (about one hour) for these meetings, due to the fact that they reside in municipalities of the region and depend on public transportation for locomotion, may have influenced the results of this variable.

The literature suggests that using CBGFM elements in educational interventions has the capacity to reduce $\mathrm{HbA} 1 \mathrm{c}$ values ${ }^{(13)}$. Nevertheless, the time factor is considered essential to obtain this result. The number of hours of contact with the health professional considered adequate for $1 \%$ reduction in $\mathrm{HbA} 1 \mathrm{c}$ was, on average, 23.6 hours, according to a longitudinal study ${ }^{(14)}$. On the other hand, in the present study, contact of participants with health professionals, considering telephone contacts, was on average 7 hours and 30 minutes.

SE concepts application aimed at minimizing barriers and increasing participants' motivation, but negative experiences such as situations in which human beings fail to implement new care behaviors can be interpreted as obstacles that are difficult to overcome, and have the capacity of limiting the scope of positive results, based on the personal beliefs of each individual ${ }^{(8)}$.

The studied sample presented expected results in relation to CBGFM practice and frequency, with emphasis on the daily frequency of CBGFM. These results are consistent with the modality of health care, in which participants of the present study are served. People with unstable blood glucose should perform CBGFM more frequently daily for adjustment of therapeutic management ${ }^{(15)}$.

As for the most frequent times for CBGFM, both before and after participation in the educational program were in descending order: in "fasting", "postprandial", "preprandial" and "before bed". The "dawn" schedule was the least mentioned. The times of accomplishment are similar to other studies that identified the same pattern of achievement in people with $\mathrm{DM}^{(11,16)}$. However, it is noted that the needs may vary for each person, depending on the type of drug treatment ${ }^{(1)}$.

Regarding the knowledge of fasting values blood glucose, the sample presented increase after participating in the educational program ( $p>0.05$ ), as well as an increase in knowledge of postprandial blood glucose values ( $p<0.05$ ). In the present study, most of the sample presented knowledge about pre and postprandial blood glucose values in the period before the educational interventions $\left(\mathrm{T}_{0}\right)$. This result can be attributed to the long diagnosis of the disease and the characteristics of the health service, which is a School Hospital, with the development of several educational activities by specially health professionals and undergraduate and graduate students.

National studies carried out in the basic health care network showed that people with DM do not have knowledge about blood glucose values, highlighting the need for specific educational programs for $\mathrm{CBGFM}^{(17-18)}$.These data suggest the need for investments for CBGFM in the primary and secondary health care sectors, with the aim of preventing and/or delaying the worsening of the disease, which may require specialized treatment in tertiary health care services.

The question of the ability to interpret capillary blood glucose results related to meals and medication also improved after educational interventions $(p<0.05)$. The topics developed in the group meetings led to discussions on the glycemic results considering the types of foods, their nutrients, glycemic indexes and also on types of medication and their respective mechanisms of action.

Reagent tape expiration date verification increased by comparing T0 with T12 ( $p>0.05)$. The observation of this item represents a necessary care to guarantee the reliability of the results obtained in CBGFM $^{(19)}$.

The disposal site of lancets and needles, referred by participants most frequently, in both study times, was the pet bottle. Educational reinforcement is needed to change this practice and to present the appropriate disposal of these materials in order to comply with the recommendations and to provide safe waste ${ }^{(1)}$. In this sense, other national studies also obtained similar results in relation to the disposal of sharps ${ }^{(20-21)}$.

Hand washing with soap and water is an essential step for infection prevention at the puncture site for $\mathrm{CBGFM}^{(22)}$ and was reported by $23(92.0 \%)$ people at $\mathrm{T}_{0}$ and $25(100.0 \%)$ at $\mathrm{T}_{12}$. The results suggest that people recognize the importance of performing hand hygiene before performing CBGFM.

When analyzing the behaviors of participants in hypoglycemia at both study times, all reported "ingesting fast-acting carbohydrates". The performance of CBGFM to verify hypoglycemia was reported by less than half of the sample in the two study times. These results suggest that people identify hypoglycemia by signs and symptoms. The blood glucose check 15 minutes after the intake was reported by four (16.0\%) people at both study times.

In situations of hypoglycemia, the correct course involves a sequence of steps that includes CBGFM to verify hypoglycemia $(<70 \mathrm{mg} / \mathrm{dL})^{(1)}$.

Concerning the question about hypoglycemia prevention, the highest frequencies were for the category "followed the meal plan with regular schedules", which obtained an increase in frequency after the interventions. In the category "frequently performed capillary blood glucose" for hypoglycemia prevention, only 11 (44.0\%) people in the T0 and 10 (40.0\%) in the T12 responded that they performed it. Hypoglycemia prevention involves the performance of CBGFM, adjustments in medication, feeding, exercise and control of alcohol intake ${ }^{(19)}$.

In the ducts facing the state of hyperglycemia, the increases in T12 are highlighted for the category: "Ingests water" and "Seeks medical care". This result suggests that participants understood that hyperglycemia may lead to a risk of dehydration ${ }^{(23)}$. 
In the issue on hyperglycemia prevention, there were high frequencies in the category "followed the food plan" and there was increase after the interventions for "administration of medicines correctly" $(p<0.05)$. Few people answered that they performed the capillary blood glucose test as a way to prevent hyperglycemia.

Hyperglycemia prevention involves the basic aspects of the treatment that should consider the CBGFM, feeding, physical exercises and drug therapy ${ }^{(1)}$.

\section{Study limitations}

The number of participants was considered an important limitation, mainly by type of study and number of variables.

\section{Contributions to Nursing and Public Health}

The study contributed to Nursing in bringing the experience of researchers to the development of educational interventions using interactive and easily applicable tools, based on the theoretical assumptions of the CST in a tertiary health care service.

\section{CONCLUSION}

After the participation of people with 2DM in the educational program for CBGFM, there were significant increases in knowledge of postprandial blood glucose values; interpretation of capillary blood glucose as a result of the interaction of diet and medications; recognition of the "weakness" symptom for hyperglycemia; and administration of medications in a correct way for hyperglycemia prevention. Outstanding results were presented, however, without statistical significance such as knowledge of the value of fasting blood glucose; records of the values obtained in the CBGFM; verification of the date of validity of the tapes; hand washing before performing CBGFM; and knowledge about hypoglycemia. In this sense, all these results may be of clinical relevance in the care of the person with DM in CBGFM.

Although $\mathrm{HbA} 1 \mathrm{c}$ did not improve immediately after the educational program, CBGFM's positive results may contribute to this long-term improvement by incorporating new knowledge into care gradually and continuously.

\section{FUNDING}

The present study was carried out with the support of the Coordination for Improvement of Higher Education Personnel - Brazil (CAPES - Coordenação de Aperfeiçoamento de Pessoal de Nível Superior) - Financing Code 001 and National Council for Scientific and Technological Development (CNPq - Conselho Nacional de Desenvolvimento Científico e Tecnológico) process number 311962/2015-7.

\section{REFERENCES}

1. Sociedade Brasileira de Diabetes. Diretrizes da Sociedade Brasileira de Diabetes: 2017-2018 [Internet]. São Paulo: Clannad. 2017 [cited 2018 Jun 02]. Available from: https://www.diabetes.org.br/profissionais/images/2017/diretrizes/diretrizes-sbd-2017-2018.pdf

2. American Diabetes Association. Standards of Medical Care in Diabetes-2018. Diabetes Care [Internet]. 2018 [cited 2018 Jul 15];41(S1):1-156. Available from: https://diabetesed.net/wp-content/uploads/2017/12/2018-ADA-Standards-of-Care.pdf

3. The ADVANCE Collaborative Group: Intensive blood glucose control and vascular outcomes in patients with type 2 diabetes. N Engl J Med [Internet]. 2008 [cited 2018 Jun 18];358(24)2560-72. Available from: https://www.nejm.org/doi/pdf/10.1056/NEJMoa0802987

4. Holman RR, Paul SK, Bethel MA, Matthews DR, Neil HA. 10-Year Follow-up of Intensive Glucose Control in Type 2 Diabetes. N Engl J Med [Internet]. 2008 [cited 2018 May 18];359(15):1577-89. Available from: https://www.nejm.org/doi/pdf/10.1056/NEJMoa0806470

5. Iquize RCC, Theodoro FCET, Carvalho KA, Oliveira MA, Barros JF, Silva AR. Educational practices in diabetic patient and perspective of health professional: a systematic review. J Bras Nefrol Med [Internet]. 2017 [cited 2018 May 22];39(2):196-204. Available from: http://www.scielo.br/ pdf/jbn/v39n2/0101-2800-jbn-39-02-0196.pdf

6. Santos JC, Cortez DN, Macedo MML, Reis EA, Reis IA, Torres HC. Comparison of education group strategies and home visits in type 2 diabetes mellitus: clinical trial. Rev Latino-Am Enfermagem [Internet]. 2017 [cited 2018 Apr 22];25:e2979. Available from: http://www.scielo. br/pdf/rlae/v25/0104-1169-rlae-25-e2979.pdf

7. Bandura A. Self-efficay: Toward a Unifying Theory of Behavioral Change. Psychological Review [Internet]. 1977 [cited 2018 Apr 12];84(2):191215. Available from: http://psycnet.apa.org/fulltext/1977-25733-001.pdf

8. Bandura A, Azzi RG, Polydoro A. Teoria Social Cognitiva: conceitos básicos. Porto Alegre: Artmed 2008. 176p.

9. Brucki SMD, Nitrini R, Caramelli P, Bertolucci PHF, Okamoto IH. Sugestões para o uso do mini-exame do estado mental no Brasil. Arq NeuroPsiquiatr [Internet]. 2003 [cited 2018 Jul 10];61(3-B):777-81. Available from: http://www.scielo.br/pdf/anp/v61n3B/17294.pdf

10. Figueira ALG, Boas LCGV, Coelho ACM, Freitas MCF, Pace AE. Educational interventions for knowledge on the disease, treatment adherence and control of diabetes mellitus. Rev Latino-Am Enfermagem [Internet]. 2017 [cited 2018 Apr 10];25:e2863. Available from: http://www. scielo.br/pdf/rlae/v25/0104-1169-rlae-25-2863.pdf

11. Ismail RC. Contribuição de um programa educativo na monitorização da glicemia capilar em pessoas com diabetes mellitus tipo 2. 2015. 117 f. [Dissertação] Escola de Enfermagem de Ribeirão Preto, Universidade de São Paulo, Ribeirão Preto. 2015.

12. Gomes LC, Coelho ACM, Gomides DS, Foss-Freitas MC, Foss MC, Pace AE. Contribution of family social support to the metabolic control of people with diabetes mellitus: A randomized controlled clinical trial. App Nurs Res [Internet]. 2017 [cited 2018 Apr 20];36:68-76. Available 
from: https://reader.elsevier.com/reader/sd/4DFB36E155F8B3C539BDDBE85F3435C6B9737A89AAA6F8F5CEF5D7EFFC384F358632517ED0 2FC5DB88BB0D0A510BAD6B

13. Greenwood DA, Young HM, Quinn CC. Telehealth Remote Monitoring Systematic Review: Structured Self-monitoring of Blood Glucose and Impact on A1C. J Diabetes Sci Technol. [Internet]. 2014 [cited 2018 Jul 13];8(2):378-389. Available from: http://journals.sagepub.com/doi/ pdf/10.1177/1932296813519311

14. Maia MA, Reis IA, Torres HC. Relationship between the users' contact time in educational programs on diabetes mellitus and self-care skills and knowledge. Rev Esc Enferm USP [Internet]. 2016 [cited 2018 Jun 04];50(1):59-64. Available from: http://www.revistas.usp.br/reeusp/ article/view/112691/110607

15. Pimazzoni Netto A, Lerário AC, Minucci W, Turatti LA. Automonitorização Glicêmica e Monitorização Contínua da Glicose. Posicionamento Oficial SBD n 1. Revista Brasileira de Medicina. Suplemento Especial n 1, 2006.

16. Veras VS, Teixeira CRS, Santos MA, Torquato MTCG, Rodrigues FFL, Zanetti ML. Perfil glicêmico de pessoas com diabetes mellitus em um programa de automonitorização da glicemia capilar no domicílio. Texto Contexto Enferm [Internet]. 2014 [cited 2018 Jun 04];23(3)609-16. Available from: http://www.scielo.br/pdf/tce/v23n3/pt_0104-0707-tce-23-03-00609.pdf

17. Franco VS, Zanetti ML, Teixeira CR, Kusumota L. Automonitorização da glicemia capilar no domicílio. Cienc Cuid Saude [Internet]. 2014 [cited 2018 Jun 04];7(1):121-127. Available from: http://periodicos.uem.br/ojs/index.php/CiencCuidSaude/article/view/4956

18. Souza VP, Santos ECB, Angelim RCM, Teixeira CRS, Martins RD. Knowledge and Practices of Users With Diabetes Mellitus on Capillary Blood Glucose Self-Monitoring at Home. Rev Pesqu: Cuid Fund [Internet]. 2018 [cited 2018 Aug 20];10(3):737-45. Available from: http://www.seer. unirio.br/index.php/cuidadofundamental/article/view/6183/pdf

19. Grossi SAA, Pascali PM. Cuidados de Enfermagem em Diabetes Mellitus[Internet]. Departamento de Enfermagem da Sociedade Brasileira de Diabetes. 2009 [cited 2018 Apr 12]. Available from: http://www.saudedireta.com.br/docsupload/13403686111118_1324_manual_ enfermagem.pdf

20. Alves SB, Souza ACS, Tipple AFV, Rezende KCD, Rezende FR, Rodrigues EG. Manejo de resíduos gerados na assistência domiciliar pela Estratégia de Saúde da Familia. Rev Bras Enferm [Internet]. 2012 [cited 2018 Aug 20];65(1): 128-34. Available from: http://www.scielo.br/pdf/ reben/v65n1/19.pdf

21. Cunha GH, Barbosa RVA, Fontenele MSM, Lima MAC, Franco KB, Fechine FV. Insulin therapy waste produced in the households of people with diabetes monitored in Primary Care. Rev Bras Enferm [Internet]. 2017 [cited 2018 Aug 20];70(3):618-25. Available from: http://www. scielo.br/pdf/reben/v70n3/0034-7167-reben-70-03-0618.pdf

22. Teixeira CRS, Zanetti ML, Landim CAP, Rodrigues FFL, Santos ECB, Becker TAC, Pinto IC, Paula FJA. Prática da utilização de lancetas ou agulhas na automonitorização da glicemia capilar no domicílio. Rev Bras Enferm [Internet]. 2012 [cited 2018 Aug 18];65(4):601-6. Available from: http://www.scielo.br/pdf/reben/v65n4/a08v65n4.pdf

23. Gallego R, Caldeira J. Complicações agudas do diabetes mellitus. Rev Port Clin Geral [Internet]. 2007 [cited 2018 Aug 18];23(5)565-75. Available from: http://www.rpmgf.pt/ojs/index.php/rpmgf/article/view/10406/10142 